Recepción: 24/ 04/2017

Aceptación: 28 / 05/ 2017

Publicación: 01/ 09/2017

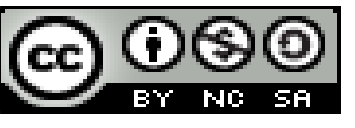

Ciencias sociales y políticas

Artículo de investigación

\title{
Los patrones culturales predominantes en las familias del sitio cárcel, una mirada desde el trabajo social
}

The predominant cultural patterns in the families of the prison site, a look from the social work

\section{Os padrões culturais predominantes nas famílias do local da prisão, um olhar do serviço social}

\author{
Patricia J. López-Mero I \\ pattylopez@hotmail.com \\ María C. Pibaque-Tigua II \\ mary35bebe@hotmail.com \\ Nancy L. Reyes-Mero III \\ nancyfj360@hotmail.com
}

Correspondencia: pattylopez@hotmail.com

I Magister en Gerencia Educativa, Diploma Superior en Intervención Social, Licenciada En Ciencias de la Educación Especialidad Castellano y Literatura, Profesora de Segunda Enseñanza Especialidad Castellano y Literatura, Licenciada en Trabajo Social Especialidad Atención a la Familia y al Desarrollo Comunitario, Universidad Laica Eloy Alfaro de Manabí, Manta, Ecuador.

II Magister en Educación Parvularia, Trabajadora Social, Licenciada en Trabajo Social, Universidad Laica Eloy Alfaro de Manabí, Manta, Ecuador.

III Magister en Trabajo Social, Trabajadora Social, Licenciada en Trabajo Social, Universidad Laica Eloy Alfaro de Manabí, Manta, Ecuador. 


\section{Resumen}

En esta investigación se ha abordado el tema de los patrones culturales existentes en las familias del sector Cárcel del Cantón Montecristi, siendo considerados como normas que se establecen en una región, ciudad, o país de acuerdo a las costumbres de un grupo de personas y que van cambiando de acuerdo a los avances, modificaciones y precisamente a esas costumbres que se van volviendo comunes en los diferentes sectores.

La familia es considerada la primera institución que transmite conocimientos, valores, costumbres y tradiciones que van formando al nuevo ser, pero en algunos casos los padres imponen ciertos estereotipos que son determinantes en la personalidad y actuaciones de los hijos/as.

En pleno siglo XXI la sociedad ha evolucionado y con ella la familia, está por voluntad propia o por exigencias del Estado, se ha visto en la obligación de cambiar su modus vivendi, se preocupa por satisfacer necesidades básicas y prioritarias que formarán al hombre y mujer competente para enfrentar los nuevos retos de la sociedad y buscar una mejor calidad de vida.

El objetivo de este estudio se centra en determinar cuáles son los patrones culturales más predominantes en las familias del sitio Cárcel y de qué manera estos inciden en las diferentes problemáticas existentes en la comunidad. Así mismo los resultados obtenidos en esta investigación, permitirán conocer de qué manera el accionar del profesional en Trabajo Social contribuye para mejorar las condiciones de vida de los habitantes de este sector potenciando sus capacidades y habilidades que busquen alternativas de solución a sus problemas.

En la presente investigación participaron 40 familias del sector Cárcel perteneciente a la zona rural del Cantón Montecristi y se aplicó un cuestionario en base a las preguntas relacionadas a alcanzar el objetivo planteado en la investigación, debido a que se plantea un avance de la investigación.

Palabras clave: patrones; familias; cultura; patrones culturales. 


\section{Abstract}

In This research has addressed the issue of existing cultural patterns in the families of the Cárcel del Cantón Montecristi sector, being considered as norms that are established in a region, city, or country according to the customs of a group of people and that they change according to the advances, modifications and precisely those customs that are becoming common in the different sectors.

The family is considered the first institution that transmits knowledge, values, customs and traditions that are forming the new being, but in some cases the parents impose certain stereotypes that are determinant in the personality and actions of the children.

In the XXI century, society has evolved and with it the family, whether by its own will or by the demands of the State, has been forced to change its modus vivendi, worries about satisfying basic and priority needs that will shape men and women competent to face the new challenges of society and seek a better quality of life.

The objective of this study is to determine which are the most predominant cultural patterns in the families of the Cárcel site and how they affect the different problems existing in the community. Likewise, the results obtained in this research will allow us to know how the actions of the professional in Social Work contribute to improve the living conditions of the inhabitants of this sector by enhancing their abilities and skills that seek alternative solutions to their problems.

In the present investigation, 40 families from the Cárcel sector belonging to the rural area of the Montecristi Canton participated and a questionnaire was applied based on the questions related to achieving the objective stated in the investigation, due to the fact that an advance of the investigation is proposed.

Keywords: patterns; families; culture; cultural patterns.

\section{Resumo}

Esta pesquisa abordou a questão de padrões culturais do sector Canton Montecristi famílias Jail existente, sendo considerada como regras estabelecidas em uma região, cidade ou país de acordo com os costumes de um grupo de pessoas e eles mudam de acordo com os avanços, modificações e precisamente os costumes que estão se tornando comuns nos diferentes setores. 
A família é considerada a primeira instituição para transmitir conhecimentos, valores, costumes e tradições que estão se formando o novo ser, mas em alguns casos os pais impõem certos estereótipos que determinam a personalidade e as ações dos filhos / as.

Na sociedade do século XXI ela evoluiu e com a sua família, é por escolha ou por exigências do Estado foi forçado a mudar seu modus vivendi, se preocupa com a satisfação das necessidades básicas e prioridades que irão formar o homem ea mulher competentes para enfrentar os novos desafios da sociedade e buscar uma melhor qualidade de vida.

O objetivo deste estudo se concentra em identificar os padrões culturais mais predominantes são as famílias da cadeia local e como estas afetam diferentes problemas existentes na comunidade. Também os resultados desta investigação permitirá saber como as ações de trabalho social profissional contribui para a melhoria das condições de vida dos habitantes deste sector, reforçando as suas competências e habilidades para buscar soluções alternativas para seus problemas.

Nesta pesquisa que envolveu 40 famílias pertencentes à área rural do setor Jail Canton Montecristi e foi aplicado um questionário baseado em questões relacionadas com a realização do objectivo definido na pesquisa, porque um avanço da investigação surge.

Palavras chave: padrões; famílias; cultura; padrões culturais.

\section{Introducción}

En 1 Los Patrones culturales son un conjunto de formas aprendidas de interactuar, en el marco de formas aprendidas de construir contextos para la acción. Son normas que se establecen en una región, ciudad, o país de acuerdo a las costumbres de un grupo de personas y van cambiando de acuerdo a los avances, modificaciones y precisamente a esas costumbres que se van volviendo comunes en algún sitio. Las formas de organizar acciones señaladas al hablar de patrones culturales se aprenden simplemente al vivirlas como prácticas recurrentes. Son hábitos que se aprenden sin tener que hacerlos conscientes. Así, por ejemplo, el abrazo se aprende simplemente siendo abrazados y abrazando a otra gente. 
En algunos sectores rurales de nuestra provincia y de acuerdo a investigación realizada se puede evidenciar que la falta de educación de las personas ha sido como consecuencia de la difícil situación económica y en otro de los casos porque algunas familias conservan la tradición de que sí los padres no estudiaron los hijos tampoco lo hacen, y se dedican a tareas o labores que realiza la familia para el sustento del hogar principalmente a la agricultura.

Los patrones imponen restricciones y límites a las organizaciones como lo son: las obligaciones de los miembros para con los demás, marcando diferencias en los conceptos de puntualidad debido a las diferencias culturales y tecnológicas.

Los patrones culturales son los comportamientos de las personas dentro de la sociedad, es decir un patrón cultural puede ser un reglamento, a qué hora es la entrada, la tolerancia, puede que todos los datos varíen dependiendo de la empresa o instituto que lo señale. En todas las sociedades deben de existir patrones culturales que regirán el comportamiento y estabilidad.

Analizando los elementos existentes entre valores y el comportamiento social nos damos cuenta que son elementos importantes, ya que se interactúa entre sí como son los elementos en que todos van relacionados por la actuación que tenga la sociedad, así como las costumbres o conducta que va dirigido conforme el tipo de sociedad sea o los miembros de la misma especie. (Ramírez, 2010).

La familia garantiza la integración sociocultural; y hay una mutua influencia entre la familia y la sociedad por lo tanto es un grupo social que aparece con el hombre y evoluciona de acuerdo a su historia.

Para Engels (Engels, 1986) la familia es un elemento activo que nunca permanece estacionado, sino que se transforma a medida de que la sociedad evoluciona de una forma de organización a otra.

En la actualidad, como en el pasado, tampoco existe un modelo único de familia; lo que nos indica que este concepto está ligado a los procesos de transformación y permanencia de los patrones socioculturales. La familia participa tanto de la diversidad de formas culturales como de la relativa homogenización de comportamientos que la cultura ocasiona. 
En la mayor parte de las sociedades actuales, el individuo tiene mayor participación en cuanto a la elección de su forma de vida y de convivencia; de igual manera las relaciones personales que configuran la familia han cambiado: cada vez se exige en ellas un mayor compromiso emocional.

La familia es donde el individuo obtiene su mayor fuente de afectos y donde pude desarrollar relaciones verdaderamente íntimas. Ya que es donde se inician las primeras relaciones de los primeros años de vida y las más significativas; Se originan situaciones e interacciones que influyen decisivamente en el desarrollo de la autoestima y la identidad personal de todos sus integrantes. Además generan condiciones que permiten al individuo aprender tanto a asumir responsabilidades como a solucionar problemas.

Las funciones que tiene la familia con respecto a los hijos son las que les:

1.- Asegura su supervivencia y sano crecimiento físico.

2.- Brinda un clima de afecto y apoyo sin los cuales el desarrollo psicológico sano no resulta posible.

3.- Facilita a los hijos una estimulación que haga de ellos seres con capacidad para relacionarse competentemente con su entorno físico y social, responder a las demandas y exigencias planteadas por su adaptación al mundo en que les toca vivir.

4.- La toma decisiones con respeto a la apertura hacia otros contextos educativos y sociales que van a compartir con la familia la tarea de educación de los hijos.

Una de las funciones primordiales que tiene la familia es permitir la aparición de cambios que permitan la expansión y el desarrollo vital de sus integrantes; esto será muy importante para el desarrollo del individuo y estos cambios abarcan:

1.- cambios en los límites, reglas, alianzas y normas entre los miembros de las familias.

2.-cambios entre miembros de la familia, que ocurren en relación con límites, reglas, alianzas y normas.

3.- cambios determinados por factores sociales, que facilitan el ajuste de la familia su contexto.

\section{Trabajo social y patrones culturales}


En el actual contexto histórico, las funciones que desarrollan los Trabajadores Sociales familiares, se convierten en importantes desafíos para mejorar cotidianamente la calidad de vida de las familias a través de múltiples objetivos:

- Contribuir el desarrollo de fortalezas y potencialidades para el enfrentamiento de sus problemas y dificultades.

- $\quad$ Promover el desarrollo de redes sociales de apoyo para las familias.

- $\quad$ Favorecer las vinculaciones constructivas entre las familias y los recursos institucionales.

La familia es el contexto de socialización, lugar de crecimiento y desarrollo personal, pero también de carencias, necesidades y problemas internos y externos. El trabajador social aplica diferentes metodologías y modelos de intervención con el objetivo de conocer, comprender e intervenir en las causas, complejidades y crisis por las que atraviesan las familias a lo largo de su ciclo vital.

La intervención del Trabajador Social se desarrolla en diferentes contextos o espacios donde los individuos generalmente se expresan con libertad, donde existen reglas, normas o patrones socioculturales establecidos y que se transmiten de una generación a otra.

El trabajador social en su desempeño profesional mantiene contactos con individuos, familias, grupos o comunidades con las que en mucho de los casos no comparte aspectos importantes de su formación cultural pero que debe respetar las particularidades y tradiciones que ellos poseen; si no lo hace resultara poca exitosa su intervención ya que los propósitos planteados a trabajar con las familias no se va a lograr porque no existirá la debida colaboración y participación durante el proceso de intervención del TS.

Cuántas veces nos desesperamos porque no logramos entender cómo las personas no captan con claridad "que lo que estamos haciendo es por su bien, que serán ellos los mayores beneficiados", ¿Cuántas puertas tocamos con la intención de acercarnos a alguien que podemos ayudar y sin embargo nos rechaza? Estos son algunos de los obstáculos que nos encontramos los TS, por tal razón se debe dar el suficiente valor a algo que debe lograrse para cualquier intervención con seres humanos: el conocimiento y la familiarización con su cultura, normas, tradiciones, reglas y costumbres establecidos en por los individuos o comunidades con las que trabaja el profesional. 
Las familias, grupos o comunidades son el reflejo de una cultura determinada y que además, en el proceso de su desarrollo generan también características muy peculiares que van a definir las formas de entender y sentir las realidades a las que se enfrentan, los patrones de conducta aceptados ante estas situaciones, las mejores formas de solución a los conflictos y las relaciones de poder que están establecidas dentro de su estructura familiar.

Por ello el Trabajador Social tendrá que familiarizarse con los patrones socioculturales y el contexto que comparte la familia con la que pretende intervenir y potenciar; de esta manera podrá conocer los aspectos culturales que allí funcionan y sobre estas bases crear alternativas más factibles para enfrentar los problemas identificados y alcanzar los objetivos planteados en la intervención social. De lo contrario pueden no comprenderse o sencillamente la familia rechazar la ayuda profesional, el Trabajador Social deberá trabajar con la familia y no para la familia.

Los actuales modelos que orientan la práctica de los trabajadores sociales conciben de una a otra forma un período de familiarización del profesional con las familias o grupos objetos de intervención. Pero no resulta suficiente dedicar tiempo en conocer algunos elementos de los patrones socioculturales o ser aceptados por sus miembros. Se requiere la aplicación de un conjunto de habilidades que el profesional debe aplicar durante su intervención.

Habilidades comunicativas.

Habilidades de mediación.

La presente investigación se enfoca en determinar los patrones culturales existentes en los habitantes del Sector Cárcel 1,2 y 3 del Cantón Montecristi y la intervención del Trabajador Social con las familias de este sector rural de la provincia de Manabí en el abordaje de las diferentes problemáticas sociales identificadas durante el estudio.

\section{Metodología}

Se realizó un estudio descriptivo, exploratorio, cualitativo en el Sector rural de Cárcel 1 del Cantón Montecristi; con una población de 40 familias que permitió analizar y detallar cuáles son los patrones culturales que tienen los grupos familiares de este sector, este estudio se realizó durante el período 2016-2017. 
Para la selección de las familias se tomó de un listado que tienen los dirigentes del sector y se escogió de manera aleatoria. Se aplicaron encuestas para conocer los Patrones Culturales predominantes en los grupos familiares y entrevistas a los profesionales e informantes claves del Sitio Cárcel 1.

\section{Análisis y resultados}

Los patrones culturales de la familia hacen referencia a aquellos comportamientos que tienen en común los miembros de una familia respecto al desarrollo de interacción social entre sus miembros.

Cada sociedad tiene una herencia cultural que determina sus patrones de comportamiento pero siendo las familias el núcleo de la sociedad no siempre una familia copia de la sociedad todos los usos y costumbres que hay en esta sociedad solamente se limita a cumplir los estándares que lo hacen ser parte de esa sociedad pero dentro de la familia hay una forma de gobierno independiente, que además varia de familia a familia por eso en ocasiones encuentras familias muy distintas a otras a pesar de ser parte de una misma comunidad, barrio, sector, un mismo partido político, una misma religión e inclusive tener un mismo ancestro familiar común, como la diferencia entre el hogar de tu padre y el hogar de un tío presentan patrones de comportamiento y usos distintos, de las generalidades de estos patrones en los núcleos familiares surge la costumbre que luego se hace ley para el territorio en que habitan las familias de determinada cultura.

Los resultados obtenidos durante la investigación indican que en el $80 \%$ de las familias encuestadas si hay patrones culturales establecidos dentro de su estructura interna y que se cumplen por cada uno de sus miembros. Estos resultados demuestran que en la zona rural donde se realizó el estudio a pesar de los cambios y evolución de la sociedad, aún se mantienen patrones culturales que en algunos de los casos han ido pasando de una generación a otra.

En relación a los patrones más predominantes están las tradiciones de las celebraciones religiosas que celebran cada año en homenaje a la Virgen Dolorosa, San Pedro y San Pablo, estas fiestas congregan a la comunidad quienes se organizan con diferentes actividades para llevar a cabo estas festividades desde hace mucho tiempo y que se continúan manteniendo en la actualidad.

Al consultar sobre la actividad laboral que desarrollan los habitantes de este sector rural de Manabí se pudo conocer que los hombres en su mayoría se dedican a la elaboración de ladrillos, 
albañilería y cría de animales domésticos, siendo éstas actividades que se ha venido cumpliendo desde hace mucho tiempo y se va transmitiendo de una generación a otra.

Las mujeres del sector en muy poco porcentaje cumplen con una actividad laboral, la mayoría se dedica a desempeñar su rol de madres y esposas dentro de su hogar; este es uno de los patrones familiares que se mantienen aún en el lugar.

En relación a la edad en la que se casan o comprometen los jóvenes del lugar en un alto porcentaje refieren que lo hacen a muy temprana edad, ya que siendo adolescentes asumen una responsabilidad que en mucho de los casos no están preparados y se ven obligados a dejar sus actividades educativas para cumplir con otras funciones propias del matrimonio.

Como resultado de los matrimonios a temprana edad también hay muchos embarazos en adolescentes, situación que se ve con mucha frecuencia en el sector de Cárcel.

Al investigar las tipologías de familias existentes en el lugar se evidencia un alto porcentaje de familias nucleares - tradicionales y familia extensa.

Al consultar a los entrevistados sobre la necesidad de que profesionales en Trabajo Social intervengan en la comunidad en el abordaje de las diferentes problemáticas sociales manifestaron que si se requiere que los profesionales de esta área desarrollen un plan de intervención a ejecutarse en conjunto con las familias y habitantes del lugar.

\section{Conclusiones}

En el sector Cárcel del Cantón Montecristi se puede evidenciar la puesta en práctica de patrones culturales que predominan en las familias de este sector rural.

Los resultados obtenidos también determinan la gran importancia que tiene la intervención del Trabajador Social en el proceso de acompañamiento, ya que este profesional desempeña las funciones específicas y su rol se enmarca en ser el orientador en la articulación para obtener una intervención integral y coordinada en base a un marco de corresponsabilidad y que las familias adquieran un mayor protagonismo en este proceso. 


\section{Referencias Bibliográficas}

Valdés Ángel, Familia y desarrollo intervenciones en terapia familiar, manual moderno, México (2007)

Gallardo Linares, Francisco J.; Escolano López, Víctor M. (2009, marzo). Informe Diversidad Afectivo-Sexual en la Formación de Docentes. Evaluación de Contenidos LGTB en la Facultad de C.C.E.E. de Málaga. Málaga (España): CEDMA 